\title{
From the Street Language of Gestures up to the Artistic Sign Language
}

\author{
Igor Vostrov \\ Russian State Specialized Arts Academy \\ Moscow, Russia
}

\author{
Valentina Kamneva \\ Russian State Specialized Arts Academy \\ Moscow, Russia
}

\author{
Varvara Romashkina \\ Russian State Specialized Arts Academy \\ Moscow, Russia
}

\begin{abstract}
The article investigates the development of sign language and its application in teaching deaf students of the Russian State Specialized Academy of Arts.

Keywords-Russian sign language; artistic sign language; the status of an interpreter; deaf and hard of hearing students; gesture; dactylology; articulation; facial expressions (mimicry); body plastic
\end{abstract}

\section{INTRODUCTION}

One of the main reasons of educational problems of the deaf and dynamics of their appearance is insufficient development of the legal and social status of the sign language and its speakers - people with disabilities in hearing and professional sign language interpreters, whose work is designed to facilitate the process of learning academic disciplines by the deaf, reduce the difficulties they face in dealing with the teachers.

\section{The Problems of Training OF A Sign LANGUAGE INTERPRETER}

However, we can't say that the problem of the status of sign language, its role in the education of the deaf and hard of hearing, the problem of the status of the translator is completely ignored by the society and the authorities. Nowadays due to the active participation of the Central Board of the Russian Society of the Deaf (VOG - the Russian abbreviation) some work on expanding of the legal space of the sign language, developing and making the regulations on the status of translators is conducted. VOG has made a major change in the law. In particular, previously sign language of the deaf was legally considered as "means of interpersonal contact" that did not allow the sign language speakers to rely on benefits and government support. Now it has its own name "Sign Language" and this fact ranks it on a par with the other languages of hearing people. The appropriate formulation allows us to consider the sign language as the state language and use it in education, arts and other spheres of our life.
In addition, now in the above-mentioned law there is the notion of "Sign Language interpreter". Now the law sees $\mathrm{him} / \mathrm{her}$ as a professional with approved qualification characteristics, in which the system of ranking is defined, the requirements for the education of an interpreter, for the length of work and etc. are specified. It is also necessary that all sign language interpreters have to get the same level of training. It means that in any town and settlement of the country the qualification category of an interpreter must testify the same level of professional competence. It is unacceptable that the professional level of the first category interpreter in Moscow would be higher than the professional level of the interpreter of the same category in Vladivostok. It is necessary to unify certifications, to use the same methods and evaluation of experts of the same level.

There is another problem related to the educational institutions. It is the existence of legal difficulties in the employment of sign language interpreters, due to lack of a unified tariff-qualifying grid of their salaries. Even the job title in various educational institutions is written in different ways: in some of them it is "a sign language interpreter", in the others - "a dactylology translator". Currently VOG is actively cooperating with the Ministry of Labour and Social Development of Russia, seeking to achieve priority in development of new tariff-qualification characteristics of work for sign language interpreters. The equal right to the education is guaranteed by the Russian Constitution to all citizens of the country. And the realization of this right for those who have hearing problems can't depend on the number of hours of teaching, which can be given to an interpreter at an educational institution.

A person with disabilities in hearing has the right to master both the Russian language skills (reading, writing) and the sign language as well. But much must be done for the effective implementation of this principle. It is required, for example, to minimize the huge disparity in the methods of teaching existing in the Russian system of education for the deaf: some students leave secondary schools (on an inclusive basis) and do not use the sign language at all, and some of them leave specialized schools and can use this 
specific means of communication. But despite this they all have equal rights to enter general or specialized higher education institutions. However it is often difficult to realize this right. VOG has been constantly and for a long time proposing to include the subject "Sign Language" into the program of secondary schools. In the opinion of VOG the Ministry of Education of Russia takes the strange position on this question. On the one hand, the law does not prohibit the inclusion of the sign language into the program of the secondary schools, on the other hand, the right to include certain disciplines, which are not in the list of base subjects, in the school curriculum only belongs to the principal or teachers' council. So in order to include the subject "Sign Language", which millions of Russian citizens who have problems with hearing are interested in, into the program of inclusive schools you must obtain the consent of each director of a school individually that is, of course, by definition impossible. But VOG does not intend to give up it and will again and again try to change the existing legislation. The existing experience gives hope for success. Many things have already been done: such notions as "Sign Language", "a sign language interpreter", as well as such fundamental legal terms as "the rights of deaf", "the culture of deaf", "the identity of deaf" have already been included into legislation.

The work on improving the legislation in the sphere of education of the citizens with disabilities in hearing is behind the current requirements of the reality of educational processes. On the one hand it can be explained by the objective difficulties - the work is new, complex, takes a lot of time. On the other hand the role of a professional sign language interpreter in improvement of effectiveness of teaching people with hearing disabilities is not sufficiently considered. Often in schools, where people with various disabilities in hearing study, it is happened to hear the opinion that it is not necessary at all to have a sign language interpreter (which is met very rarely nowadays), and that any student which can hear something can be used as an interpreter. Such a short-sighted strategy in practice leads to a sharp drop in the level of mastering school disciplines by the students, especially the humanities, since a conceptual system of a student - interpreter and his translation capabilities can't meet the requirements of teaching even the most basic themes on Literature, Philosophy, Sociology, Management, and other subjects. A student-interpreter, even using the good sign language, translates in accordance with his/her own level of knowledge of the subject and culture in general. As a result a student does not translate a teacher adequately, but actually adapts it.

Often, schools and institutes tend to save salary schedule by getting rid of staff interpreters, hiring the interpreters only for the period of teaching a certain discipline. And this tactic does not lead to success, because in the complex institutes, such as art colleges, an interpreter must understand not only the humanities, but also other professional disciplines, be familiar with the basic concepts of the specifics of the institute (for example, artistic terms). In order to do effective job an interpreter must be "immersed" in the subject and life of the institutions, its specific features, specificity of students. And this is possible only working in the staff of such institution for a long period of time. It is the indisputable fact: the longer an interpreter works for an institution the higher the quality of his/her work and the level of students 'progress in studies.

Another most pressing problem is the adequacy of payment of the professional interpreter's job. A linguist translator of a foreign language gets usually more than a thousand rubles per an hour, and a translator of the sign language gets two hundred rubles on average, though the work of the latter is much more complicated in the professional and the technological sense. For example, an "ordinary" translator has the opportunity to ask the lecturer to pause, using it for more accurate selection of words and grammar. A sign language interpreter when translating the lecture has no such possibility, he/she actually has to work as a simultaneous interpreter, translating at the same time any lecture in literary language, keeping true the context and meanings. Otherwise a deaf student, having opened a textbook, would not recognize what was said about in a lecture and, as a result, would not have mastered the material. This means that an interpreter, translating simultaneously a lecture, should still have time in addition for further explanation of abstruse points.

Perhaps the concealment of the problems, described above, explains largely why they have not been solved yet or resolved ineffectively. Here is the sample. In August, 2013 the State adopted the Federal law that takes into account observance of the rights of the disabled. But the state has forgotten to reinforce it by financing for providing the establishment of additional conditions (payment to translators, creating barrier-free environment, acquisition of specialized equipment, computers, textbooks and others). As a result, all these deprive many people with disabilities of their rights to education, they can't improve their professional level. For example, a deaf cabinetmaker is denied the entrance a professional college, a motor impaired - an art college and etc., and there are so many such facts. It is clear that it is not always enough to expand the legal space, protecting the rights of people with disabilities, we need more measures from the government to implement useful legal innovations.

We should also remember that a number of problems encountered in training people with hearing disabilities in higher and secondary specialized educational institutions, originate not in the universities, but earlier, in secondary schools. In

Russian schools students are taught in accordance with the verbal-tonal system, which has been proving its efficiency for many decades. But the deaf, finishing school, are eager to find a team of their own kind, where they can communicate freely, to obtain information. It's extremely difficult for the deaf to live and work side by side with hearing people, because communication requires constant physical and intellectual powers. But it is also difficult for a person with hearing problems to find psychologically acceptable environment because few people around 
understand the sign language, let alone know how to communicate in it.

It is well known that deaf children are not always born to parents with hearing problems. There's a whole social group in which hearing parents have deaf children, that often leads to strained relations in a family. Few people are involved in this problem in Russia, but the solution of it, as international experience shows, does not need a lot of effort and money. For example, in the Baltic countries hearing parents of deaf children learn the sign language that let them avoid many conflicts between themselves and their children, as well as between such families and the external environment.

All these unresolved problems have led to the fact that almost 6 million of our citizens of all ages who have hearing problems spend the most part of their lives in stressful conditions, not being able to communicate with hearing people, to realize their legitimate rights not only to education, but sometimes even to work. Nowadays there is a real need to include teaching the sign language in the secondary school. It is necessary to learn Sign language as well as to learn Russian. Then we will get not deaf or hard of hearing disabled people, but valuable members of society who are able to understand and interpret the information coming to them from the world and successfully use it to integrate with the society. Besides we will get millions of healthy people who are able to help the deaf in their eagerness to become useful to society, to accelerate their social adaptation. And this, mind you, will be not only help to your neighbor, but also a civil act, the proof of significant growth in morality of Russian people.

\section{The Place AND the Role of Sign Language IN THE SYSTEM OF HIGHER ART EDUCATION FOR THE DEAF}

The experience of use of sign language in teaching the hearing impaired people creative professions of an artist and painter has been long and hard accumulated by the teachers of RGSAI through mistakes and successes.

The concept of its use in the educational process also has been enriched and developed.

It is appropriate to recall that the birth of the Specialized Academy of Arts is bound up with the problem of the use of sign language in teaching of deaf students. About thirty years ago (in 1984) in the Higher Theater College names after B.V. Shchukin a specialized course was organized for deaf actors. It was the first experiment of teaching disabled in hearing students in accordance with the full program of higher education. Before that there had been only the specialized training studio at the Theatre of Facial Expressions and Gestures where the young people studied 23 years. By the time of graduation from the College both the students and their teachers had some experience, based largely on a special opinion about sign language of the deaf. To implement these knowledge the Experimental laboratory of theater education and creativity of the Deaf (ELTOTG the Russian abbreviation) was established, which was soon transformed into the Specialized Institute of Arts (since 2013 - the Academy). The establishment of such institute, that also became the only experimental "platform" (stage) in the country, allowed to develop and apply in teaching creative professions the concept "non-loan-translation gestural speech " (Russian Sign Language) as opposed to the concept of a common "loan-translation sign language", in which a verbal phrase is based on the syntax of the Russian language, every word in it is accompanied by a gesture, that helps to understand the phrase. From the first days of foundation of the Institute Russian Sign Language (RSL) was taught and developed by the remarkable teachers - such as I. Timoshevskaya, I. Moskvina, I. Ginsberg, A. Martianov, E. Griglovichute. All they are the graduates of that experimental course of Shchukin Higher College on the basis of which the Specialized Institute of Arts was formed.

Professor G.L. Zaitseva laid down the foundations of Russian Sign Language. Years of its development, application, working out of the concept of Russian sign language strengthened us in understanding that Sign Language is an independent system of communication and an independent language, which is used by the deaf people. Considering this special system of communication as the special language we have recognized the features (human, psychological, social) of the people who use it, the community of these people generally, we got acknowledged of the existence of a particular subculture. It was extremely important to understand all this when teaching them creative professions, because, as experience has shown, only relying on Russian sign language teachers get the opportunity to develop a unique creative individuality of students. In development of varies teaching methods the teachers of the Academy are guided by originality and uniqueness of the learners stipulated by hearing problems.

The understanding of the special nature of Russian Sign Language has been formed over the years. The primary element of the language is not a word in a verbal communication in any language, but a visual image.

Another feature of Russian Sign Language is the impossibility of written fixation since Sign Language exists only in connection with a specific person in a context of a particular conversation. You can write down gestures, gestural phrase, but only the one who has made this record will be able to understand it. Sign language is an exclusive language for direct communication. Constant, every moment interaction between this one who expounds on it and that one who perceive it is a fixture of the language.

In the studying process and in the further life and work it is obligatory for an educated deaf person to use two languages - Russian and Russian sign language. However, the sign language in the Academy - is not only means of studying and communication. For the future actors it is also means of artistic creation, the material for a scenic image. Taking into consideration this important feature, teaching, scientific and methodical work of the teachers of RGSAI is conducted simultaneously in two directions: the development of sign language as a means of communication (there are special classes at the Faculty of Fine Arts) and formation of the artistic sign language (for students of the Theatre Faculty). 
Sign language we meet in everyday life (in the streets, in metro) is not quite that one an actor uses on the stage. Saving the main peculiarity - the figurative nature of Russian gestural speech, the artistic Sign language is more expressive, various, aesthetic and beautiful than in private life. Studying at the Academy and developing themselves intellectually and emotionally, students enrich their Sign Language, broaden its communicative and artistic possibilities, finding out new non-verbal expressions of their thoughts and emotions.

Russian Sign Language consists of such elements as a gesture, dactylology (writing the words in letters with fingers), articulation, mimicry, body plastic, sense of rhythm and music. The more difficult thought which is necessary to pass to a partner the more elements a passer uses. That is exactly why a huge volume of work is conducting to perfect all mentioned elements. The actors must become proficient in this subject. All this let them to show image-sense content and artistic originality of the national and foreign drama to the spectacles, to connect sign language with music.

Another peculiarity of this method of teaching at the theatre faculty in the Academy is that the teachers taking part in the process of teaching acting, stage movement, dance, sense of music and rhythm, sign language are hard of hearing themselves. Their help is really inestimable.

Despite the unique experience of creation and developing the artistic sign language the teachers of RGSAI don 't hurry to assume the honorary title of "the founders" of all these methods, theories and the language, because there are still few people who use the artistic sign language, it is not practically used in everyday life and in specialized schools where deaf children study. They would like that Sign Language created in the Specialized Academy of Arts would go out of its walls and be used widely in the studying process and in general.

\section{CONCLUSION}

The whole number of unsettled problems mentioned in the beginning of the article prevents the street sign language to be improved. One of the main problems is the terrific luck of sign language interpreters. It doesn't concern only the Academy, it concerns the whole country. The reason of this, as it was already said, is that sign language for a long time has not had the language status and the skillfully developed teaching programs as well. As a result it hasn 't been taught neither at specialized schools for the deaf nor at secondary schools. In fact the deaf children were forbidden to use the language acceptable for them. So it is not surprising that most school-leavers who enter the Academy don't know sign language. Only inside the Academy they start learning it trying to use the gestures as perfect as it's possible. It becomes the basic for studying the artistic sign language which allows to interpret the works of literature.

The scenic practice of the deaf students in the Academy shows that a special atmosphere of understanding is created at the performances for the deaf due to the artistic sign language. This atmosphere is full of live emotions and sympathy, one can see the dialogue between the actors and the audience. Sign language can help the disabled people to touch the Art in full value. It is necessary to help this unique artistic language go out to the streets, to become the means of communication for millions of the deaf. 